\title{
Intragastric administration of Lactobacillus casei BL23 induces regulatory FoxP3+RORyt+ T cells subset in mice
}

\author{
N.G. Cortes-Perez , D. Lozano-Ojalvo, M.A. Maiga, S. Hazebrouck and K. Adel-Patient \\ UMR Service de Pharmacologie et d'Immuno-Analyse, CEA, INRA, Université Paris-Saclay, 91191 Gif-sur-Yvette, France; \\ naima.cortes-perez@cea.fr
}

Received: 26 September 2016 / Accepted: 29 January 2017

(c) 2017 Wageningen Academic Publishers

OPEN ACCESS (1) (1)(2) RESEARCH ARTICLE

\begin{abstract}
Many studies have highlighted the immunomodulatory properties of the probiotic strain Lactobacillus casei BL23. Recently, we demonstrated the ability of this strain to modulate the Th2-oriented immune response in a mouse model of cow's milk allergy based on the induction of a Th17-biased immune response. The probiotic function of $L$. casei has been also linked to gut-microbiota modifications which could been potentially involved in the immune regulation; however, its precise mechanism of action remains poorly understood. In this regard, recent studies suggest that gut microbiota induces a specific subset of CD4+FoxP3+ Treg cells that also express RORyt+, the specific transcription factor of Th17 cells. This new type of regulatory $\mathrm{T}$ cells, called type $3 \mathrm{Treg}$, displays suppressive function during intestinal inflammation, participating in inflammation control. We thus explored the ability of L. casei BL23 to specifically induce type 3 Treg cells, both in vitro and in vivo. Our results showed that intragastric administration of L. casei BL23 to mice induces local and systemic FoxP3+ RORyt+ type 3 Treg cells that could then participate in the beneficial effects of L. casei BL23 in different intestinal-related disorders.
\end{abstract}

Keywords: Lactobacillus casei, type 3 regulatory T cells, FoxP3, RORyt, immunomodulation

\section{Introduction}

Lactic acid bacteria (LAB) have been used for centuries for preserve and produce fermented foods. The most representative LAB species belong to Lactobacillus genus. Some LAB strains naturally colonise human mucosal surfaces such as gastrointestinal tract and vagina and are then considered part of the human microbiota (Walter, 2008). Several studies have demonstrated the immunomodulatory properties of different strains of lactobacilli (Foligne et al., 2007; Kechaou et al., 2013; Santos Rocha et al., 2014). For instance, Lactobacillus casei BL23 represents a potential candidate strain for the treatment of intestinal-related disorders such as intestinal inflammation and food allergies (Del Carmen et al., 2011; Hazebrouck et al., 2009).

Accordingly, we previously demonstrated that intragastric administration of recombinant $L$. casei BL23 expressing a major cow's milk allergen partially corrects the Th2- biased immune response in a mouse model of cow's milk allergy (Hazebrouck et al., 2006, 2009). Additionally, oral treatment with the BL23 strain protects mice against 1,2-dimethylhydrazine (DMH)-induced colorectal cancer (Lenoir et al., 2016). Interestingly, in both models, the immunomodulation was related to the induction of a fine-tuned Th17-oriented immune response, although the cellular mechanisms underlying lactobacillus-mediated protection are currently unclear (Lenoir et al., 2016).

The plasticity of the CD4+ T cells is a well-documented fact. Upon environmental stimuli, CD4+ T cells differentiate into diverse subsets that express lineage-specific transcription factors, such as T-bet, GATA-3, ROR $\gamma$ t and Foxp3 for Th1, Th2, Th17 and T regulatory cells (Treg), respectively (Weaver et al., 2007). This capacity may hold the key to managing immune response properly; nevertheless, the decision of $\mathrm{T}$ cells to balance into either Th or Treg cells is strongly driven by cytokine signals from environment (Yang et al., 2008; Zhou et al., 2008). In an elegant study, 
Ayyoub and coworkers found that a significant proportion of Tregs also express high levels of RORyt (Ayyaub et al., 2009). Lately, the ability of Treg double-positive FoxP3+RORyt+ to suppress effector $\mathrm{T}$ cells was reported in a mouse model of inflammation (Tartar et al., 2010). In this context, Ohnmacht and coworkers have recently shown that gut microbiota, could induce a specific subset of regulatory CD4+FoxP3+ T cells that also express the Th17 transcription factor, ROR $\gamma t$ (Ohnmacht et al., 2015). These FoxP3+ROR $y \mathrm{t}+$ double positive cells, designated as type 3 Treg cells, were shown to be involved in the regulation of type 2 immune responses and allergic reactions (Ohnmacht et al., 2015). Lochner and coworkers also described the enhanced suppressive abilities of ROR $\mathrm{t}+$ Treg cells during intestinal inflammation (Lochner et al., 2015). Considering the immunomodulatory properties of $L$. case $i$ BL23, these findings encouraged us to investigate the ability of $L$. case $i$ BL23 to induce this specific subset of Treg cells.

\section{Experimental procedures}

\section{Preparation of live bacterial inoculum}

L. casei BL23 (Acedo-Félix et al., 2003) was grown at $37{ }^{\circ} \mathrm{C}$ on De Man, Rogosa and Sharpe (MRS; Difco, BD, Le Pont de Claix, France) agar plates. A single colony was selected and grown in $5 \mathrm{ml}$ of MRS broth at $37^{\circ} \mathrm{C}$ for $18 \mathrm{~h}$ in closed tubes, without agitation, as previously described (Hazebrouck et al., 2007). A $100 \mu \mathrm{l}$ aliquot was then transferred into $10 \mathrm{ml}$ of fresh MRS broth and incubated at $37^{\circ} \mathrm{C}$ until an optical density at $600 \mathrm{~nm}$ of 1 was reached. Bacterial cultures were then centrifuged and washed three times with phosphate buffered saline (PBS). For in vitro assays, bacterial concentration was adjusted at $1 \times 10^{7} \mathrm{cfu} / \mathrm{ml}$ in RPMI medium supplemented with $10 \%$ foetal calf serum (FCS) and $2 \mathrm{mM} \mathrm{L}$-glutamine. To perform in vivo experiments, bacteria were resuspended in saline buffer $(\mathrm{NaCl} 0.9 \%)$ at $1 \times$ the volume of the pellet sediment collected, which resulted in a concentration of $\sim 5 \times 10^{10}$ cells $/ \mathrm{ml}$, as described (Hazebrouck et al., 2009).

\section{Splenocytes isolation and in vitro co-incubation with Lactobacillus casei}

Spleens were recovered from six naïve BALB/cI mice (fiveweek-old; Centre Elevage René Janvier, Le Genest-Saint-Isle, France) as previously described (Lenoir et al., 2016). Briefly, splenocytes were recovered by mechanical disruption using gentleMACS ${ }^{\oplus}$ Dissociator (Miltenyi Biotec $\mathrm{GmbH}$, Germany). After red blood cell lysis $\left(180 \mathrm{mM} \mathrm{NH}_{4} \mathrm{Cl}, 17\right.$ $\mathrm{mM} \mathrm{Na}{ }_{2}$ EDTA), spleen cells were recovered and pooled in RPMI medium supplemented with $10 \%$ FCS and $2 \mathrm{mM}$ L-glutamine. The splenocytes were then co-incubated with L. casei $\mathrm{BL} 23$ for $1 \mathrm{~h}$ (at $37{ }^{\circ} \mathrm{C}$ and $10 \%$ of $\mathrm{CO}_{2}$ ), using a ratio of 10 bacteria per splenic cell. After co-incubation, splenocytes were centrifuged and washed twice with PBS, in order to remove bacteria from the culture. Recovered spleen cells were resuspended in supplemented RPMI containing antibiotics $(50 \mu \mathrm{g} / \mathrm{ml}$ of gentamicin, 100 units/ $\mathrm{ml}$ of penicillin and $100 \mu \mathrm{g} / \mathrm{ml}$ of streptomycin), and cell culture was pursued for 4 days. The co-incubation assays were performed at least in triplicate. A mock control was prepared in a similar fashion without bacteria (untreated splenocytes). On day 4, spleen cells were centrifuged and collected for cell phenotype analyses by flow cytometry.

\section{In vivo experiments}

All animal experiments were performed according to European Community rules of animal care and with the authorisation $\mathrm{N}^{\circ}$ 91-368 368 of the French Veterinary Services. Experiments were covered by agreement No. 2009-DSV-074 from the Veterinary Inspection Department of Essonne (France). Three-week-old female BALB/cJ (CERJ) were housed under pathogen-free conditions in the animal facility of the Institute of Biology and Technology (iBiTeCS, CEA-Saclay, France). The immune response triggered by the intragastric administration of bacteria was evaluated as previously described (Hazebrouck et al., 2009). Mice were intragastrically administered with $L$. casei BL23 $\left(\sim 1.5 \times 10^{8} \mathrm{cfu} /\right.$ mouse/administration; $\left.\mathrm{n}=8\right)$ or PBS as a control $(n=8)$ for five consecutive days. Three days after the last administration, animals were sacrificed by cervical dislocation. Cells were recovered from the spleen, mesenteric lymph nodes (MLN) and Peyer's patches (PP) by mechanical disruption as previously reported (Adel-Patient et al., 2011). The isolation of lamina propria (LP) cells was performed as described (Bernink et al., 2013), with some modifications. Briefly, after spleen and MLN collection, the small intestine was removed and fat cleared. The intestinal content was removed by PBS flushing, PP were recovered and the small intestine was then opened and cut into small pieces. In order to eliminate epithelial cells, intestinal sections were incubated three times in a solution of Hank's balanced salt solution (without $\mathrm{Ca}^{2+}$ and $\mathrm{Mg}^{2+}$ ) containing $2 \mathrm{mM}$ of EDTA and $10 \mathrm{mM}$ of HEPES $\left(15 \mathrm{~min}, 37^{\circ} \mathrm{C}\right.$ and $250 \mathrm{rpm})$. The remaining tissues were then digested with a solution of RPMI containing $10 \mathrm{mM}$ of HEPES, $25 \mu \mathrm{g} /$ $\mathrm{ml}$ collagenase (Libérase, Roche, Sigma-Aldrich) and $10 \mathrm{U} /$ $\mathrm{ml}$ of DNAse I (Roche, Sigma-Aldrich) $\left(45 \mathrm{~min}, 37^{\circ} \mathrm{C}\right.$ and $250 \mathrm{rpm}$ ). LP cells were recovered from digested tissue by mechanical disruption using the gentleMACS Dissociator (Miltenyi Biotech, Bergisch Gladbach, Germany). Cells from spleen, MLN and PP were then phenotyped by flow cytometry. Each mouse was treated individually.

\section{Phenotyping of $T$ cells populations}

All cells were recovered in a solution of PBS containing 2\% FCS and 1 mM EDTA, and afterwards filtered through a 70-100 $\mu \mathrm{m}$ cell strainer. Fc receptors were blocked using anti-CD16/CD32 (clone 2.4G2, BD Pharmingen, Franklin 
Lakes, NJ, USA). T cell populations were analysed using the following antibodies: anti-CD4-FITC (clone GK1.5, BD Pharmingen), anti-CD4-PE-CY7 (clone GK1.5, eBioscience, San Diego, CA, USA), anti-CD4-BV785 (clone RM4-5, Biolegend, San Diego, CA, USA), anti-FoxP3-PE (Miltenyi Biotech) and anti-RORyt-FITC (clone 46419, Imgenex, San Diego, CA, USA), anti-IL-17A-PerCP-Cy5.5 (clone eBio17B7, eBioscience). Approximately 70,000 cells were acquired using a NovoCyte flow cytometer (ACEA Bioscience, Inc., San Diego, CA, USA), and in some experiments, a Guava EasyCyte Plus cytometer (GuavaTechnologies, Hayward, CA, USA) was used. Analyses were performed using NovoExpress ${ }^{\mathrm{Tm}}$ software (Version 1.0.0, ACEA Biosciences, Inc.). Samples were first inspected in all light scatter patterns and fluorescence channels to confirm quality, and abnormal populations were excluded. Unlabelled processed samples were used for reporting the percentage of positive cells (Johansson et al., 2014). Lymphocytes were typed as follows: Treg were defined as CD4+FoxP3+; Th17 as CD4+RORyt+ and type 3 Treg as FoxP3+RORyt+ within CD4+ population (Ohnmacht et al., 2015). Frequency of interleukin (IL)-17 producing cells within the CD4+ cells was also measured (CD4+IL17+ cells).

\section{Statistical analysis}

Data analysis was performed using the GraphPad Prism V.5.01 (GraphPad, La Jolla, CA, USA). Experiments were analysed using an unpaired $t$ test. The two-tailed unpaired Mann-Whitney test was used to evaluate differences between two groups. In all experiments, a value of $P<0.05$ was considered significant (" $P<0.05$, ** $P<0.01$, **** $P<0.001)$.

\section{Results}

\section{Co-incubation of splenocytes with Lactobacillus casei BL23 enhanced frequency of FoxP3+RORyt+ double positive T cells}

The induction of FoxP3+RORyt+ double positive T cells by $L$. casei BL23 was first evaluated by an in vitro approach using splenocytes from naïve mice. The frequency of FoxP3+RORyt+ cells was initially assessed within the whole population of singlet live cells. As shown in Figure 1A, the interaction of splenocytes with $L$. casei BL23 led to a significant increase of FoxP3+RORyt+ double positive cells $(P<0.05)$. We then analysed the frequency of FoxP3+RORyt+ cells within CD4+ cells. Although, the frequency of this Treg

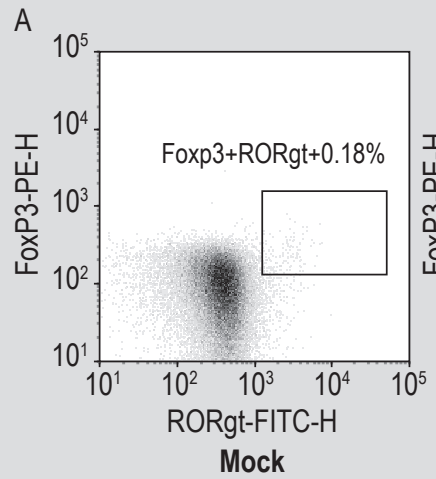

B

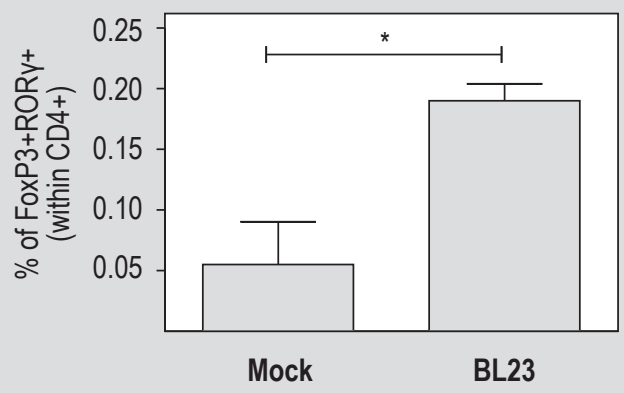

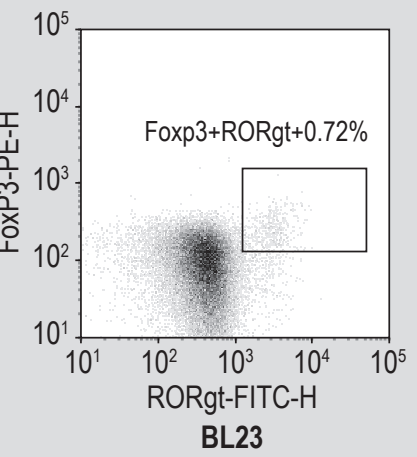

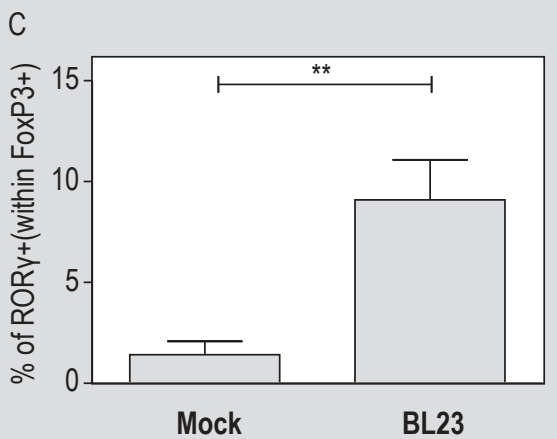

D
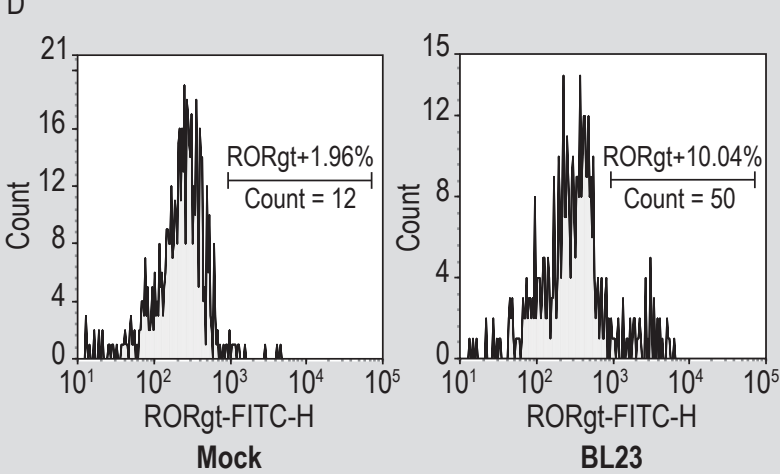

Figure 1. Analysis of regulatory T cells induced by Lactobacillus casei BL23 in vitro. Gating strategies are shown in Supplementary Figure S1. (A) Representative dot plot showing the frequency of FoxP3+RORyt+ double-positive cells within whole single-gated cells. (B) Type 3 Treg cells were defined as percent of double-positive FoxP3+ RORyt+ cells within CD4+ population. (C) Expression of RORyt+ within the CD4+FoxP3+-gated cells. (D) Histogram showing the frequency of RORyt+ within FoxP3+ cells. Results (mean \pm standard deviation) are representative of at least two independent experiments performed in triplicate. Unpaired $t$ test was used to compare data, ${ }^{*} P<0.05,{ }^{* *} P<0.01,{ }^{* *} P<0.001$. 
subset was very low within CD4+ cells population (mean $0.1 \% \pm 0.01$ standard deviation), we demonstrated a 3 -fold increase of this population after interaction with $L$. casei $(P<0.05$, Figure 1B). To confirm this observation we also analysed the expression of ROR $\gamma \mathrm{t}+$ within the FoxP3+ cells (Figure 1C and 1D). Actually, L. casei BL23 enhanced the expression of RORyt+ within the FoxP3+ cells $(P<0.01)$.

\section{Intragastric administration of Lactobacillus casei BL23 positively modulates type-3 Treg cells}

We then explored the in vivo effect of intragastric administration of $L$. casei BL23 on the equilibrium of Treg/Th17 cells. Mice ( $\mathrm{n}=8 /$ group) were treated for five consecutive days with $L$. casei BL23 or PBS. The distribution of CD4+ cells, as well as that of FoxP3+ or RORyt+ cells within the CD4+ population was not affected by $L$. case $i$ administration in any of the lymphoid organ studied (Supplementary Figure S3). Conversely, within the CD4+ population, a statistically significant increase in FoxP3+ROR $\gamma \mathrm{t}+$ double positive cells was observed in the spleen $(P<0.01), \mathrm{PP}(P<0.05)$, and LP $(P<0.01)$ of mice treated with L. casei BL23 compared with the control group (Figure 2A-C). Furthermore, a concomitant trend to the reduction of this cell subset was observed in MLN in five out eight mice) (Figure 2D). Conversely, the production of IL-17 by CD4+ T cells was not significantly affected after the intragastric administration of L. casei BL23 (Figure 2E-

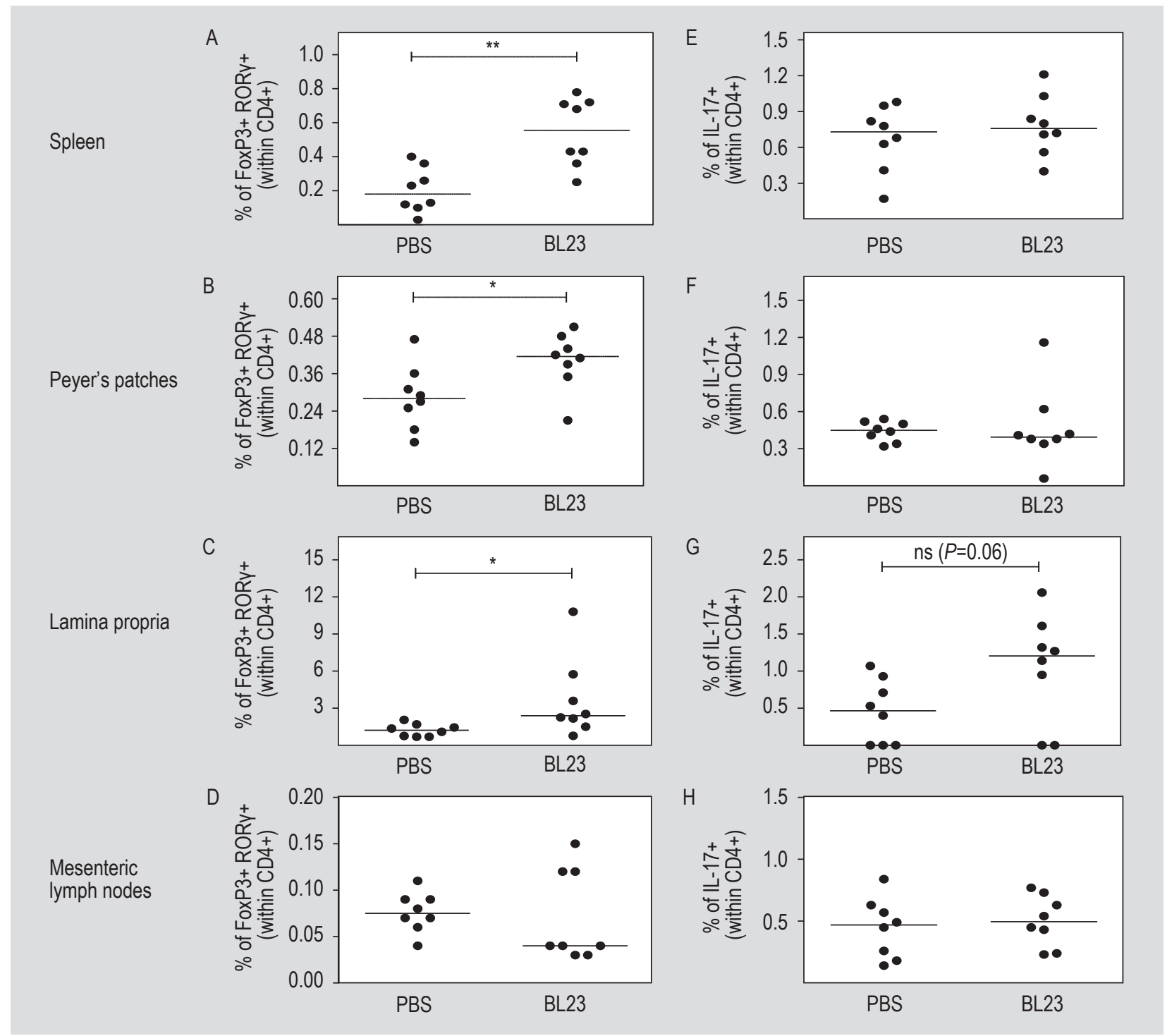

Figure 2. Effect of intragastric administration of Lactobacillus casei BL23 on the Th17 and T regulatory FoxP3+ RORYt+ cell populations cells from splenocytes, Peyer's patches, lamina propria and mesenteric lymph nodes. (A-D) Percentage of doublepositive FoxP3+ RORyt+ cells within CD4+ population and (E-H) percentage of interleukin (IL)-17+ cells within CD4+ T cells. Each data point represents one individual mouse and lines represent the median values. The Mann-Whitney test was used for statistical analyses. ${ }^{*} P<0.05,{ }^{* *} P<0.01,{ }^{* * *} P<0.001$. 
$\mathrm{H})$, although a tendency $(P=0.06)$ to increase was observed in the LP. This thus suggests that classical Th17 cells were not induced by $L$. casei administration.

\section{Discussion}

Different studies have reported the beneficial properties of some bacteria, thus considered as probiotic. However, even if some underlying mechanisms have been evoked (for a review, see Van Baarlen et al., 2013), little is known about the immune mechanisms engaged by 'good' bacteria to positively affect the host immune system. In this context, Ohnmacht and colleagues have elucidated a potential mechanism induced by the gut microbiota and regulating type 2 immune response. This mechanism involves the induction of a new Treg subset designated as type 3 Treg (Ohnmacht et al., 2015). Alongside suppressive and antiinflammatory features, the particularity of this novel $\mathrm{T}$ subset is the concomitant expression of FoxP3, the transcription factor associated to Treg cells, and RORyt+, the transcription factor associated to Th17 cells (Lochner et al., 2015). Accordingly, our results showed evidence that L. casei BL23 increases the frequency of type 3 Treg both in vitro and in vivo. The induction of this Treg population could explain, at least in part, the immunomodulatory capacity already demonstrated for $L$. casei BL23. Further studies are underway to confirm this hypothesis, notably their role in the protective effects of L. casei BL23 on different pathologies, such as intestinal inflammation or food allergies.

\section{Supplementary material}

Supplementary material can be found online at https:// doi.org/10.3920/BM2016.0174.

Figure S1. Gating strategy used to assess the frequency of type 3 RORyt+ Treg induced after in vitro stimulation of splenocytes with Lactobacillus casei.

Figure S2. Gating strategy used to assess cellular population in mice orally administrated with Lactobacillus casei.

Figure S3. Influence of oral administration of Lactobacillus casei BL23 on cellular responses ( $\mathrm{T}$ cells, regulatory T cells and Th17 cells).

\section{Acknowledgements}

DLO, SH and KAP are part of the COST Action FA1402 entitled: Improving Allergy Risk Assessment Strategy for New Food Proteins (ImpARAS). DLO acknowledges his FPU Grant (MECD) and financial support through AGL2014$59771 R$ project. We thank Luis Bermudez-Humaran for comments that greatly improved the manuscript and AhLeung S, Przybylski-Nicaise L for technical support.

\section{Conflict of interest}

The authors declare that they have no conflict of interest.

\section{References}

Ayyoub, M., Deknuydt, F., Raimbaud, I., Dousset, C., Leveque, L., Bioley, G. and Valmori, D., 2009. Human memory FOXP3+ Tregs secrete IL-17 ex vivo and constitutively express the T(H)17 lineagespecific transcription factor RORgamma t. Proceedings of the National Academy of Sciences of the USA 106: 8635-8640.

Acedo-Félix, E. and Pérez-Martínez, G., 2003. Significant differences between Lactobacillus casei subsp. casei ATCC 393T and a commonly used plasmid-cured derivative revealed by a polyphasic study. International Journal of Systematic and Evolutionary Microbiology 53: 67-75.

Adel-Patient, K., Wavrin, S., Bernard, H., Meziti, N., Ah-Leung, S. and Wal, J.M., 2011. Oral tolerance and Treg cells are induced in $\mathrm{BALB} / \mathrm{c}$ mice after gavage with bovine $\beta$-lactoglobulin. Allergy 66: 1312-1321.

Bernink, J.H., Peters, C.P., Munneke, M., Te Velde, A.A., Meijer, S.L., Weijer, K., Hreggvidsdottir, H.S., Heinsbroek, S.E., Legrand, N., Buskens, C.J., Bemelman, W.A., Mjösberg, J.M. and Spits, H., 2013. Human type 1 innate lymphoid cells accumulate in inflamed mucosal tissues. Nature Immunology 14: 221-229.

Del Carmen, S., De LeBlanc, A.M., Miyoshi, A., Rocha, C.S., Azevedo, V. and LeBlanc, J.G., 2011. Potential application of probiotics in the prevention and treatment of inflammatory bowel diseases. Ulcers 2011: 1-13.

Foligne, B., Nutten, S., Grangette, C., Dennin, V., Goudercourt, D., Poiret, S., Dewulf, J., Brassart, D., Mercenier, A. and Pot, B., 2007. Correlation between in vitro and in vivo immunomodulatory properties of lactic acid bacteria. World Journal of Gastroenterology 13: 236-243.

Hazebrouck, S., Oozeer, R., Adel-Patient, K., Langella, P., Rabot, S., Wal, J.M. and Corthier, G., 2006. Constitutive delivery of bovine beta-lactoglobulin to the digestive tracts of gnotobiotic mice by engineered Lactobacillus casei. Applied and Environmental Microbiology 72: 7460-7467.

Hazebrouck, S., Pothelune, L., Azevedo, V., Corthier, G., Wal, J.M. and Langella, P., 2007. Efficient production and secretion of bovine betalactoglobulin by Lactobacillus casei. Microbial Cell Factories 6: 12 .

Hazebrouck, S., Przybylski-Nicaise, L., Ah-Leung, S., Adel-Patient, K., Corthier, G., Langella, P. and Wal, J.M., 2009. Influence of the route of administration on immunomodulatory properties of bovine betalactoglobulin-producing Lactobacillus casei. Vaccine 27: 5800-5805.

Johansson, U., Bloxham, D., Couzens, S., Jesson, J., Morilla, R., Erber, W. and Macey, M., 2014. Committee for standards in haematology. guidelines on the use of multicolour flow cytometry in the diagnosis of haematological neoplasms. British Journal of Haematology 165: 455-488. 
Kechaou, N., Chain, F., Gratadoux, J.J., Blugeon, S., Bertho, N., Chevalier, C., Le Goffic, R., Courau, S., Molimard, P., Chatel, J.M., Langella, P. and Bermúdez-Humarán, L.G., 2013. Identification of one novel candidate probiotic Lactobacillus plantarum strain active against influenza virus infection in mice by a large-scale screening. Applied and Environmental Microbiology 79: 1491-1499.

Lenoir, M., Del Carmen, S., Cortes-Perez, N.G., Lozano-Ojalvo, D., Muñoz-Provencio, D., Chain, F., Langella, P., De Moreno de LeBlanc, A., LeBlanc, J.G. and Bermúdez-Humarán, L.G., 2016. Lactobacillus casei $\mathrm{BL} 23$ regulates $\mathrm{T}(\mathrm{reg})$ and Th17 $\mathrm{T}$-cell populations and reduces DMH-associated colorectal cancer. Journal of Gastroenterology 51: 862-873.

Lochner, M., Wang, Z. and Sparwasser, T., 2015. The special relationship in the development and function of $\mathrm{T}$ helper 17 and regulatory T cells. Progress in Molecular Biology and Translational Science 136: 99-129.

Ohnmacht, C., Park, J.H., Cording, S., Wing, J.B., Atarashi, K., Obata, Y., Gaboriau-Routhiau, V., Marques, R., Dulauroy, S., Fedoseeva, M., Busslinger, M., Cerf-Bensussan, N., Boneca, I.G., Voehringer, D., Hase, K., Honda, K., Sakaguchi, S. and Eberl, G., 2015. The microbiota regulates type 2 immunity through ROR $\gamma \mathrm{t}^{+}$Tcells. Science 349: 989-993.

Santos Rocha, C., Gomes-Santos, A.C., Garcias Moreira, T., De Azevedo, M., Diniz Luerce, T., Mariadassou, M., Longaray Delamare, A.P., Langella, P., Maguin, E., Azevedo, V., Caetano de Faria, A.M., Miyoshi, A. and Van de Guchte, M., 2014. Local and systemic immune mechanisms underlying the anti-colitis effects of the dairy bacterium Lactobacillus delbrueckii. PLoS ONE 9: e85923.
Tartar, D.M., VanMorlan, A.M., Wan, X., Guloglu, F.B., Jain, R., Haymaker, C.L., Ellis, J.S., Hoeman, C.M., Cascio, J.A., Dhakal, M., Oukka, M. and Zaghouani, H., 2010. FoxP3 ${ }^{+}$ROR $\gamma \mathrm{t}^{+} \mathrm{T}$ helper intermediates display suppressive function against autoimmune diabetes. Journal of Immunology 184: 3377-3385.

Van Baarlen, P., Wells, J.M. and Kleerebezem, M., 2013. Regulation of intestinal homeostasis and immunity with probiotic lactobacilli. Trends in Immunology 34: 208-215.

Walter, J., 2008. Ecological role of lactobacilli in the gastrointestinal tract: implications for fundamental and biomedical research. Applied and Environmental Microbiology 74: 4985-4996.

Weaver, C., Hatton, R., Mangan, P. and Harrington, L., 2007. IL-17 family cytokines and the expanding diversity of effector $\mathrm{T}$ cell lineages. Annual Review of Immunology 25: 821-852.

Yang, X., Nurieva, R., Martinez, G., Kang, H., Chung, Y., Pappu, B., Shah, B., Chang, S., Schluns, K.S., Watowich, S., Feng, X., Jetten, A. and Dong, C., 2008. Molecular antagonism and plasticity of regulatory and inflammatory $\mathrm{T}$ cell programs. Immunity 29: 44-56.

Zhou, L., Lopes, J., Chong, M., Ivanov, I., Min, R., Victora, G., Shen, Y., Du, J., Rubtsov, Y., Rudensky, A., Ziegler, S. and Littman, D., 2008. TGF-beta-induced Foxp3 inhibits $\mathrm{T}(\mathrm{H}) 17$ cell differentiation by antagonizing RORgammat function. Nature 453: 236-240. 